\title{
Friction stir spot welding of CFRP and aluminum alloy with themoplastic adhesive
}

\author{
K. Tanaka ${ }^{1}$, T. Teramura ${ }^{1}$, T. Katayama ${ }^{1} \&$ K. Nishiguchi ${ }^{2}$ \\ ${ }^{1}$ Department of Biomedical Engineering, Doshisha University, Japan \\ ${ }^{2}$ Mazda Motor Corporation, Japan
}

\begin{abstract}
In recent years, due to serious environmental issues, the development of the gasoline mileage improvement technology has been essential in the automotive industry which occupies most of the transportation section, which accounts for $18 \%$ of domestic carbon dioxide emissions. Weight-saving of the car body can contribute to improving the gasoline mileage. Carbon fiber reinforced plastics (CFRP) are expected to be used as materials for structural parts. Because of their expensive cost, however, CFRP monocoque body is only applied to luxury sports cars. To meet the demand of the reduction of the weight and affordable cost, a multi-materials body, a complex with CFRP and conventional materials such as aluminium and steel, has been proposed. For the adoption of a multi-material body, joining technologies for two different materials are necessary to be developed, and reasonable and practical high performance joining process has to be developed. Aluminum alloy has the properties such as weight-saving, high specific strength, formability, recyclability, and high designability. The conventional joining methods between CFRP and aluminium alloy are mechanical joining such as bolts, self-piercing rivets and adhesive joining. However, mechanical joining has the disadvantage of weight increasing and adhesive joining needs severe control of the materials and requires many tasks on management and workers. In this study, friction stir spot welding (FSSW) technology using thermoplastic adhesive was developed to join CFRP plate and aluminum plate in order to overcome these problems. CFRP plate and aluminum plate were successfully joined by the FSSW and the tensile shear strength of $10.9 \mathrm{MPa}$ was obtained.

Keywords: friction stir spot welding, carbon fiber reinforced plastics, aluminum, thermoplastic adhesive.
\end{abstract}




\section{Introduction}

In recent years, due to the serious environmental issues, the development of the gasoline mileage improvement technology is essential in the automotive industry, which occupies most of the transportation section that accounts for $18 \%$ of domestic carbon dioxide emission [1-3]. The technology includes improvement of the efficiency of the engine, the energy regeneration system, and the weightsaving of the car body. Especially, weight-saving of the car body can contribute to improving the gasoline mileage $[4,5]$. Various materials including high tensile steel, aluminum alloy, and CFRP have been used for weight-saving [3]. For realizing the weight-saving of the car body, CFRP are expected to be used as materials for mass-produced components in the automotive industry because of their high specific strength and specific rigidity and light weight property. However, because of their expensive cost, CFRP monocoque bodies are only applied to luxury sports cars and the application of CFRP is limited to only some parts in the mass production cars [6]. To meet the demand of the reduction of the weight and affordable cost of automobile, a multi-material body, which is a complex body with CFRP and conventional materials such as aluminum and steel, has been proposed [7, 8]. For the adoption of a multi-material body, joining technologies for two different materials are necessary to be developed, and a reasonable and practical high performance joining process has to be developed. Aluminum alloy has the properties such as weight-saving, high specific strength, formability, recyclability, and high designability $[9,10]$. It is expected to increase the use of the aluminum alloy for the car body in the future [3]. The mechanical joining such as bolts, self-piercing rivets and adhesive joining are used a lot for joining CFRP and the different kinds of materials such as aluminum alloy [11, 12]. However, these joining methods has to be avoided, since the mechanical joining increases the weight of the body, and the liquid adhesive joining needs severe contoroll of the materials and require many tasks on management and workers. Friction Stir Spot Welding (FSSW) that can be converted from the spot welding machine which has already been used for the car production line can be a candidate for the solution. FSSW is the joining method using solid-phase joining, and is used for a different kind of metallic joining as a substitute of resistance spot welding [11]. Recently FSSW technology for the joining of Carbon Fiber Reinforced Thermoplastics (CFRTP) and metal materials has been developed [13, 14]. Althogh CFRTP is expected to be used in car body due to high mass productivity with short molding time, CFRP using thermoset resin for a matrix is mainstream in the real application of composite materials to the car body. Therefore the FSSW technology that can be applied to the joining of CFRP and metal materials is necessary to be developed.

In this study, the hot press joining of the CFRP and the aluminum alloy with thermoplastic adhesive was carried out, and the tensile shear strength was evaluated to assess the potential of the thermoplastic adhesive. The FSSW was carried out to the same materials system as hot press joining and the tensile shear strength of FSSW was compared with that of hot press joining. 


\section{Materials and experimental procedure}

\subsection{Materials}

Carbon fiber reinforced epoxy matrix composite (CFRP plate, Mitsubishi Rayon, MM-1/982X) and the aluminum alloy (Al plate, A5052) with the size of $20 \mathrm{~mm} \times 100 \mathrm{~mm} \times 2 \mathrm{~mm}$ were used for the materials to be joined. For the thermoplastic adhesive, nonwoven fabric (Prototype, Kuraray, $50 \mathrm{~g} / \mathrm{m}^{2}$ ) of polyamide 6 (PA6, Ube Industries, 1013B) was used. The melting point of the PA6 measured by the differential scanning calorimetry (Shimazu Corporation, DSC-60) is $220^{\circ} \mathrm{C}$ and the thermal decomposition temperature with a $5 \%$ weight loss temperature measured by thermogravimetry (Shimazu Corporation, TGA-50) is $395^{\circ} \mathrm{C}$.

\subsection{Hot press joining}

Hot press joining was conducted by hot press machine in order to assess the potential of the tensile shear strength of the PA6 adhesive as the reference. The surface of CFRP plate and Al plate where they were joined were cleaned by acetone and polished by abrasive paper of \#80. The PA6 nonwoven fabric was inserted between the CFRP plate and Al plate as shown in Fig. 1. The specimens were joined by the hot press machine (AS ONE, AH-2003) with one-, two-, threeand four-ply of the PA6 nonwovens. The upper die was heated to $300^{\circ} \mathrm{C}$, and the lower die remained at room temperature as shown in Fig. 2. The press pressure was set at $3 \mathrm{MPa}$ and holding time was set for 15 seconds. Cross section of the specimen was observed by the digital microscope (Keyence, VHX-5000). Tensile shear tests was conducted by the universal testing machine (Shimazu Corporation, Autograph AG-100kN Xplus, maximum load capacity: $100 \mathrm{kN}$ ) at a constant cross-head speed of $1.7 \times 10^{-5} \mathrm{~m} / \mathrm{s}(1.0 \mathrm{~mm} / \mathrm{min})$. The tensile shear strength $\tau$ in the following eqn (1) was calculated by maximum load $F_{\max }$ and joining area $A$ $(20 \mathrm{~mm} \times 12.5 \mathrm{~mm})$. The fracture surface was observed by the digital microscope.

$$
\tau=\frac{F_{\max }}{A}
$$

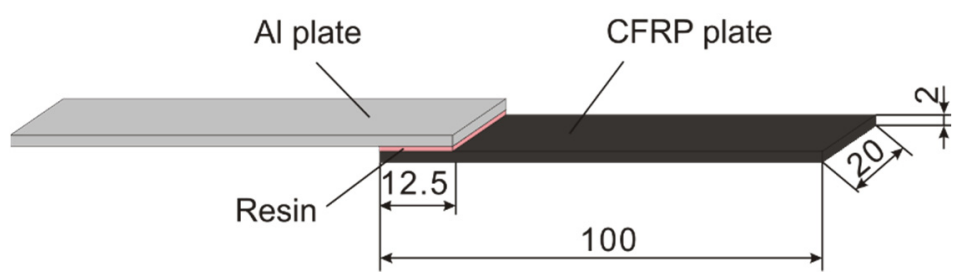

Figure 1: Schematic image of specimen layup. 


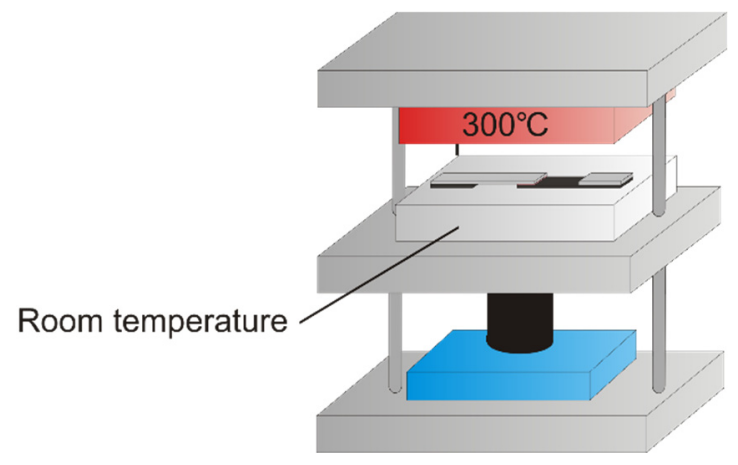

Figure 2: $\quad$ Schematic image of hot press joining.

\subsection{Friction stir spot welding (FSSW)}

The FSSW was performed by an SKD61 (HRC48 \pm 2 ) tool with a diameter of $10 \mathrm{~mm}$ having a tip projection shape of $2 \mathrm{~mm}$ in diameter and $0.4 \mathrm{~mm}$ in height, attached to a mini milling machine (COSMO KIKAI, FK-500), to the centre of the lap joint as shown in Fig. 3. As for the friction stir condition, the number of revolutions of $43.7 \mathrm{~s}^{-1}\left(2620 \mathrm{~min}^{-1}\right)$ and the stir time of 30 seconds are set to be constant and three load conditions of $550 \pm 25 \mathrm{~N}, 650 \pm 25 \mathrm{~N}$, and $750 \pm 25 \mathrm{~N}$ are used to press the tool on the specimen. These joined specimens were referred as FSSW550N, FSSW650N, and FSSW750N, respectively. The temperature histories of the centre of the back side of Al plate at every 0.5 seconds were measured using the graphic recorder (OMRON, ZR-RX40 Portable Multi Logger) with $\mathrm{K}$ type thermocouples which were inserted between CFRP plate and Al plate during FSSW as shown in Fig. 4. Cross section of the joined specimens was observed by the digital microscope. The tensile shear strength of the specimen was calculated described in Section 2.2.

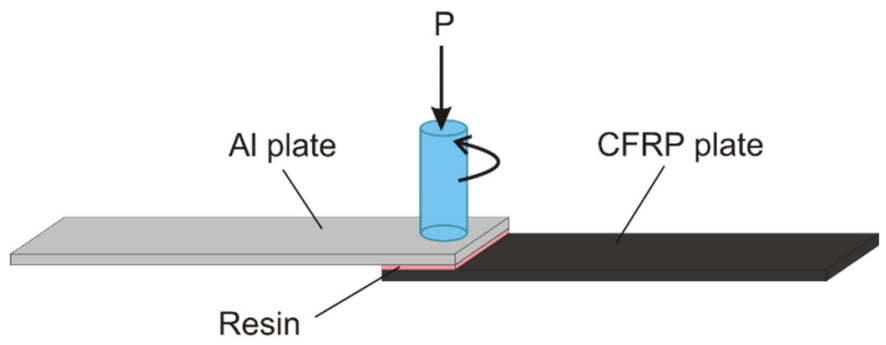

Figure 3: $\quad$ Schematic image of FSSW. 


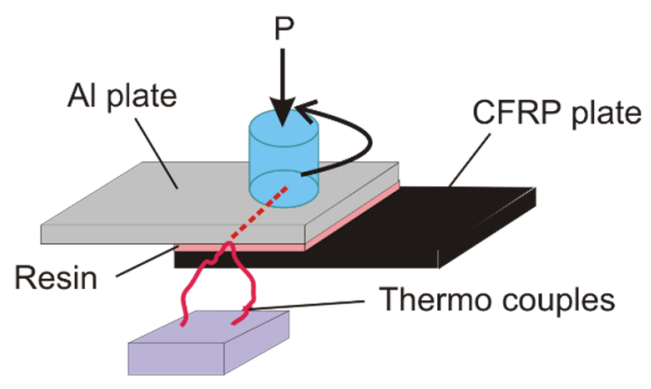

Figure 4: Schematic image of measuring the temperature histories with $\mathrm{K}$ type thermocouples.

\section{Results and discussion}

\subsection{Tensile shear strength of hot press joined specimens}

The tensile shear strength of hot press joining is shown in Fig. 5. The maximum tensile shear strength of $8.4 \pm 2.2 \mathrm{MPa}$ is obtained for the specimens with two-ply of PA6 nonwoven fabrics. As the adhesive thickness increases above two-ply, the joining strength becomes lower. This tendency is correspond to the reported results [15]. The cross sections of the specimen with one-ply and two-ply of PA6 nonwoven fabrics for adhesive are shown in Fig. 6. The resin layers are formed between CFRP plate and Al plate. While the layer has a large amount of cavity for the specimen with one-ply of PA6 nonwoven fabric as shown in Fig. 6(a), cavity was not observed for the specimen with two-ply of PA6 nonwoven fabric as shown in Fig. 6(b). The lower tensile shear strength for the specimen with oneply of PA6 nonwoven fabric is considered to be the lack of resin. The observations

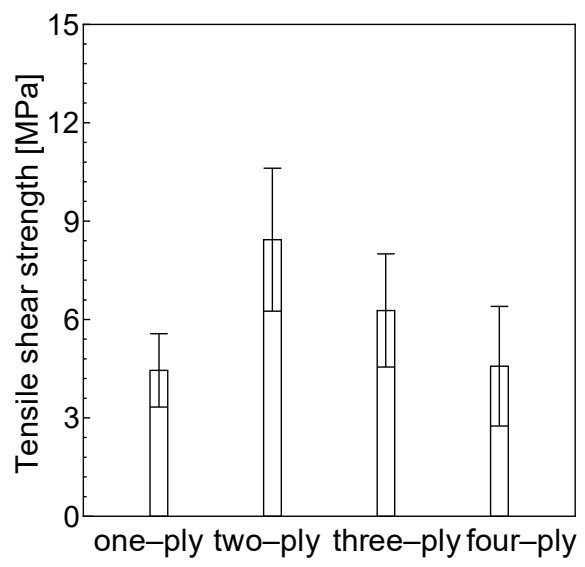

Figure 5: Tensile shear strength of hot press joining with different ply of PA6 nonwoven fabric. 

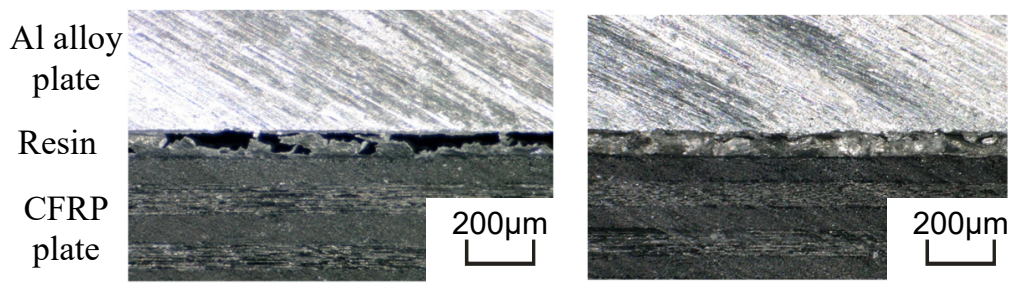

(a) one-ply of PA6 nonwoven fabric (b) two-ply of PA6 nonwoven fabric

Figure 6: Microscope observations of cross sections of hot press joined specimens.

of the fracture surface of specimens with one-ply and two-ply of PA6 are shown in Fig. 7. The resin layer fractured the specimen with one-ply of PA6 nonwoven fabric as shown in Fig. 7(a). In contrast, for the specimen with two-ply of PA6 nonwoven fabrics as shown in Fig. 7(b), some pieces of CFRP were observed on the Al plate. This result suggests that the joined strength is similar of larger than that of shear strength of CFRP. As for the specimen with two-ply of PA6, The failure load was $1922 \pm 478 \mathrm{~N}$ and this value is comparable to the necessary strength which is reported to be $1922 \mathrm{~N}$ for spot welding of aluminum alloys [16].

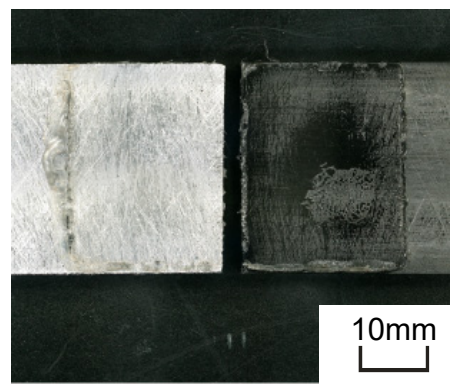

(a) one-ply of PA6 nonwoven fabric

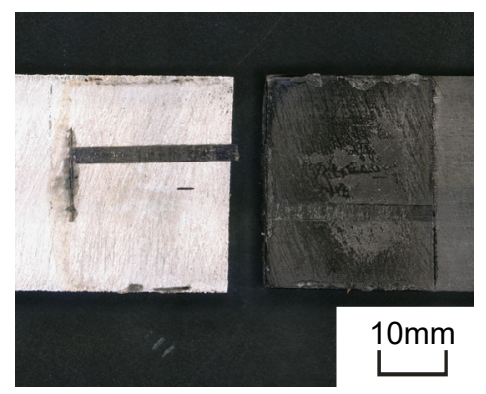

(b) two-ply of PA6 nonwoven fabric

Figure 7: Microscope observations of fracture surfaces of hot press joined specimens.

\subsection{Temperature measurement result during FSSW}

The temperature history of the back of the Al plate under three different kinds of load measured by the thermocouples is shown in Fig. 8. Two lines of $220^{\circ} \mathrm{C}$ of melting point $\left(\mathrm{T}_{\mathrm{m}}\right)$ of PA6 and $340^{\circ} \mathrm{C}$ of the $5 \%$ weight loss temperature $\left(\mathrm{T}_{\mathrm{d}}\right)$ of PA6 are plotted in the figure. When the load was $550 \mathrm{~N}, 650 \mathrm{~N}$, and $750 \mathrm{~N}$, the time above the melting point was 22,24 , and 27 seconds, respectively, and the time above the $5 \%$ weight loss temperature was 0,21 , and 24 seconds, 
respectively. In order to clear the process window of temperature, to understand the rate of weight loss at high temperature and the decomposition temperature of the epoxy which is the matrix of CFRP is the key issues to be evaluated.

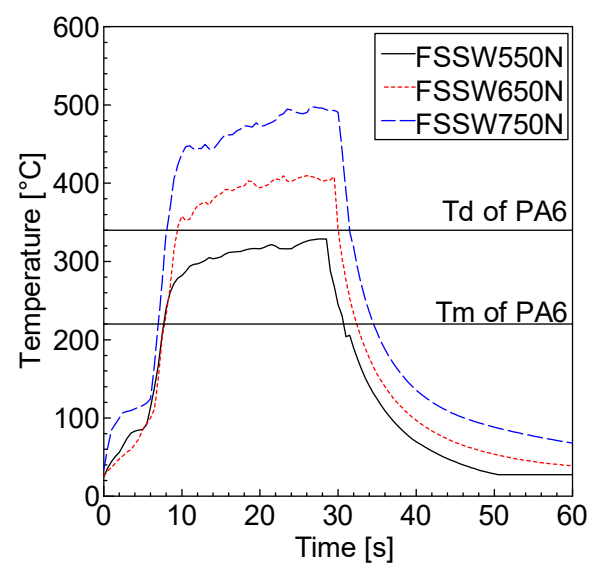

Figure 8: Temperature history of Al plate.

\subsection{Tensile shear strength of FSSW specimens}

The failure load of the specimen joined by the FSSW and the tensile shear strength $(\tau)$ are shown in Figs 9 and 10. As the load to press the tool is higher, the failure load and the tensile shear strength are higher. Particularly in FSSW750N, the failure load was $1504 \pm 317 \mathrm{~N}$ and the tensile shear strength was $6.0 \pm 0.65 \mathrm{MPa}$. The fracture surface of FSSW550N, FSSW650N, and FSSW750N are shown in Fig. 11. Only the centre area of PA6 nonwoven fabric area is melted and only the

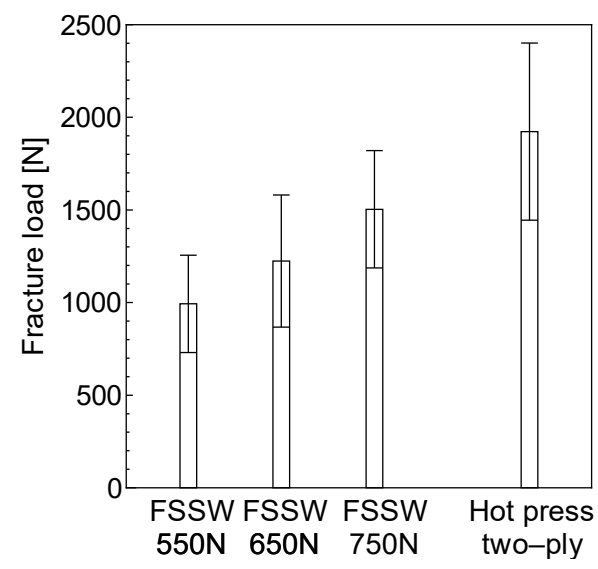

Figure 9: Fracture load of specimens. 


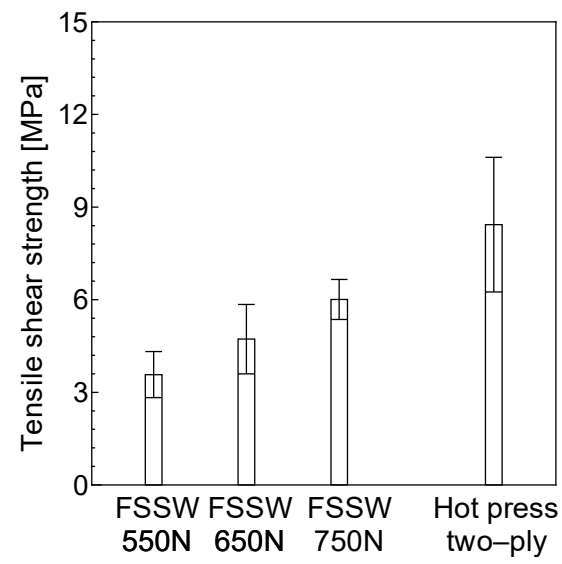

Figure 10: Tensile shear strength of specimens.

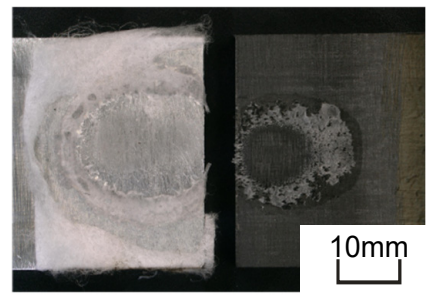

(a) FSSW550N

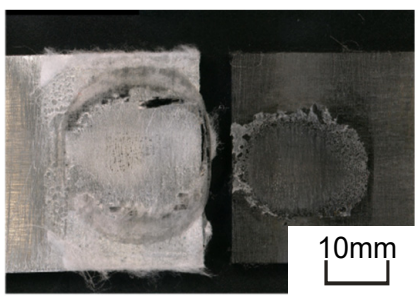

(b) FSSW650N

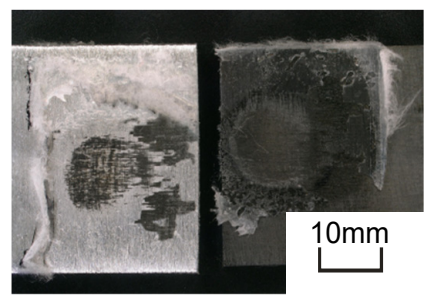

(c) FSSW750N

Figure 11: Microscope observations of fracture surfaces of specimen.

melting area of the PA6 contributes to the adhesion. The melted areas of the PA6 on the CFRP are measured (Fig. 12). The tensile shear strength that is calculated by dividing the failure load in Fig. 9 by each melted area is shown in Fig. 13. The tensile shear strength for FSSW750N is $10.9 \pm 2.79 \mathrm{MPa}$, and the value was higher than the adhesion shear strength of the hot press joining. 


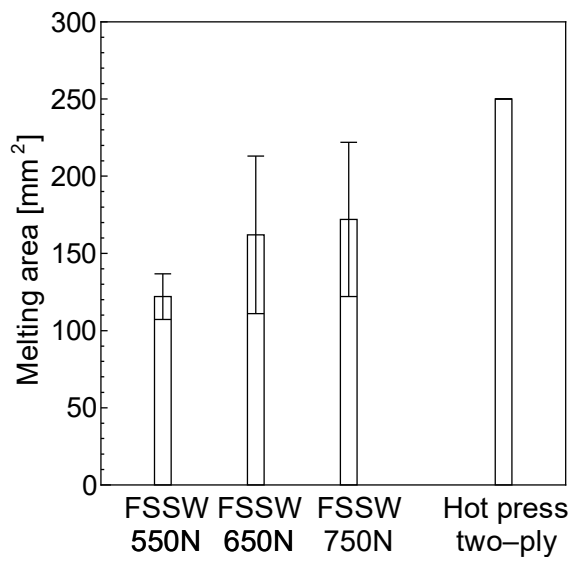

Figure 12: Melting area of PA6 on CFRP plate.

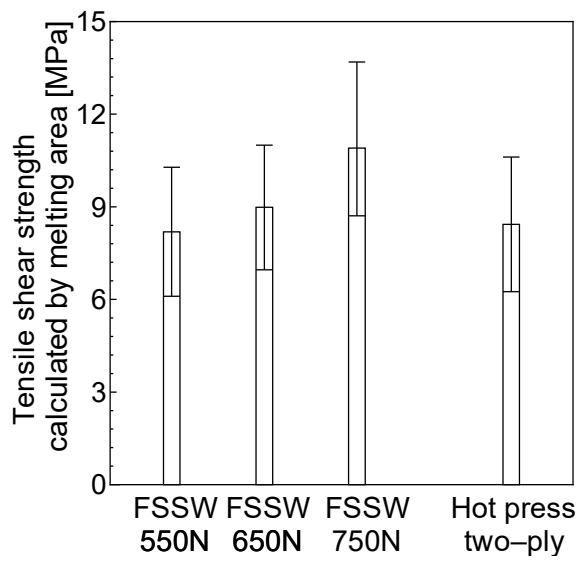

Figure 13: Tensile shear strength calculated by melting area.

\section{Conclusion}

The hot press joining of the CFRP and the aluminum alloy with thermoplastic adhesive was carried out, and the tensile shear strength was evaluated to assess the potential of the thermoplastic adhesive. The Friction Stir Spot Welding (FSSW) was carried out to the same materials system as hot press joining and the tensile shear strength of FSSW was compared with that of hot press joining. The investigation yielded the following conclusions:

1. Failure load of the specimen made by the hot press joining was $1922 \pm$ $478 \mathrm{~N}$, and the tensile shear strength calculated by the overlapped area was $8.4 \pm 2.2 \mathrm{MPa}$. 
2. As load to press the tool on the specimen increased, the high value was obtained in the failure load of the specimen made by the friction stir spot welding with thermoplastics adhesive. The highest value of $1504 \pm 317 \mathrm{~N}$ was shown in the press load of $750 \mathrm{~N}$. CFRP plate and Al plate were successfully joined by the FSSW and the tensile shear strength of $10.9 \pm$ 2.79 MPa was obtained.

\section{References}

[1] Ministry of the Environment Government of Japan, The transition of internal $\mathrm{CO}_{2}$ emissions by department, Statistic of the Environment, 2015. www.env.go.jp/doc/toukei/contents/

[2] Ministry of the Environment Government of Japan, The transition of $\mathrm{CO}_{2}$ emissions and primary socio-economic activities amount, Statistic of the Environment, 2015. www.env.go.jp/doc/toukei/contents/

[3] Yamane, K., The latest trends of weight saving in automobile, Weight saving technology in automobile, NTS book, pp. 3-7, 2014.

[4] Shia, R., Tsumuraya, K., Nakatsuka, S. \& Takahashi, J., Effect of automobile lightning by CFRP on the world energy saving, The Ninth Japan International SAMPE Symposium, pp. 8-13, 2005.

[5] Ministry of Land, Infrastructure, Transport and Tourism Government of Japan, The fuel efficiency and $\mathrm{CO}_{2}$ emissions of passenger vehicles, Statistic of the fuel efficiency in automobile, 2015. www.mlit.go.jp/jidosha/ jidosha fr10 000010.html

[6] Iwano, M., Plastic automobile parts, Kogyo Chosakai Publishing, p. 85, 2010.

[7] Itakura, K., Application examples and assignments of aluminum alloy in automobile, Materials development and technics for improvements of strength, stiffness, and toughness in automobile weight saving, Technical Information Institute, pp. 329-338, 2015.

[8] Miyazaki, Y., Dissimilar metal joining technologies for steel sheet and aluminum alloy sheet in auto body $\sim$ Correspondences for multi-material body , Materials development and technics for improvements of strength, stiffness, and toughness in automobile weight saving, Technical Information Institute, pp. 480-490, 2015.

[9] Ko, Y., An introduction of automotive materials, Tokyo Denki University Press, pp. 83-96, 2009.

[10] Sato, T., Metallurgy of Light Alloys, Corona Publishing, pp. 12-13, 2011.

[11] Fukumoto, M., Junction technology of dissimilar material based on friction stirring, Weight saving technology in automobile, NTS book, pp. 129-138, 2014.

[12] Ochiai, I., The process of thin plate structures, Nikkan Kogyo Shimbun, pp. 211-214, 1998. 
[13] Nagasaki, K., Onoda, T., Okada, T. \& Nakata, K., Direct dissimilar joining of aluminum alloys and polyamide 6 by friction lap joining, Quarterly Journal of the Japan Welding Society, 32 (4), pp. 235-241, 2014.

[14] Mazda Motor Corporation, Japan Patent P2015-131443.

[15] da Silva, L.F.M., Rodrigues, T.N.S.S., Figueiredo, M.A.V., de Moura, M.F.S.F. \& Chousal, J.A.G., Effect of adhesive type and thickness on the lap shear strength, The Journal of Adhesion, 82 (11), pp. 1091-1115, 2006.

[16] JIS Z 3140, Method of inspection for spot weld, 1989. 